\title{
Author Correction: Optimization of in vitro culture media for improvement in yield of Navara ancient Indian medicinal rice
}

\author{
Manish Solanki $^{1}$ (D) Anshika Sinha ${ }^{1}$ (D) Lata I. Shukla ${ }^{1}$ (])
}

Received: 22 July 2019 / Accepted: 24 July 2019 / Published online: 9 August 2019

(c) King Abdulaziz City for Science and Technology 2019

\section{Author Correction: \\ 3 Biotech (2019) 9:270 \\ https://doi.org/10.1007/s13205-019-1797-2}

In the original article, on the page 270 the increasing order of fresh weight of calli is for the 10 days post-inoculation as against 15 days mentioned in the text (Table 4). The authors regret the mistake. Authors thank Mr. Haifang Jin, for critically reading the article and enabling us to provide this correction.

The original article can be found online at https://doi.org/10.1007/ s13205-019-1797-2.

Lata I. Shukla

drlatashukla07@gmail.com

1 Department of Biotechnology, School of Life Sciences,

Pondicherry University, Kalapet, Puducherry 605014, India 